\title{
The Demand for Fertilizer: A Critical Review
}

\author{
Khalil A. Hamdani and Nadeem Ul Haoue*
}

Four studies [2, 3, 7, and 11] and a comment [1] on the demand for fertilizer have appeared in this Review. All fit similar demand specifications to aggregate data for roughly the same time period. Surprisingly, each presents distinctly different results. Together, the studies provide 28 estimates of the price elasticity of fertilizer demand of which only seven are significant and even these range from -1.21 to $0.46 .^{1}$ The studies are split evenly on the policy issue of price subsidization.

The implications of these results are difficult to assess. If little consensus is possible among researchers on empirical estimates from the same data, the policy implications of the estimates can be seriously discounted. Whether this is a necessary or extreme assessment is the principal question of interest posed by the current state of research on the demand for fertilizer. The aim of this paper is to review the past research with the intention to assess the conflicting estimates. We begin with a brief statement of the underlying methodology; we then critically review each past study; and, finally, we conclude with an over-all assessment of past research on the demand for fertilizer.

\section{METHODOLOGY}

The theory of input demand derives the fertilizer demand function from the consumer demand functions faced by the profit-maximizing farmer [4]. ${ }^{2}$ Let $q$ be the quantity of fertilizer demand and $p$ the price. Then, if there are $\mathrm{m}$ outputs and $\mathbf{n}$ inputs in farm production, the derived demand function is

$$
\mathrm{q}=\mathrm{f}\left(\mathrm{p}_{1}, \ldots, \mathrm{p}_{\mathrm{m}}, \ldots, \mathrm{p}_{\mathrm{m}+\mathrm{n}}\right)
$$

* At the time of the writing of this paper, Dr. Hamdani was Senior Research Economist at the Pakistan Institute of Development Economics. Mr. Haque is Research Economist in the same Institute. The authors wish to express their sincere appreciation of the editorial
help rendered by S. H. H. Naqavi.

The significance criterion is the two-tail t-test at the 90 percent probability level. All studies use the two-tail test except one [11]. In view of the occurrence of positive elasticities, we favour the use of the two-tail test.

2Occasionally, the assumption of profit maximization is denied in the formulation of the demand function for fertilizer. See for instance $[11, p .182]$ and $[12, p .221]$. The assumption
is necessary in the derived demand model, nonetheless. 
If the system is closed in the sense that demand is unrelated to other prices and the function is homogeneous of degree zero, then any price, for example, $p_{1}$, can serve as a numeraire and all other prices can be expressed relative to it. So

$$
\mathrm{q}=\mathrm{f}\left(1, \mathrm{p}_{2}^{*}, \ldots, \mathrm{p}_{\mathrm{m}+\mathrm{n}}^{*}\right)
$$

where $p_{i}^{*}$ is the relative price $p_{i} / p_{1}$. Generally, $q$ is negatively related to input price if the input is fertilizer or its complement, and positively related to output price if production of the output requires fertilizer.

Frequently, the demand function is reduced to its minimum dimension. If there is just one output and one input, fertilizer, with a relative price, $p_{f}^{*}$, then the above expression is reduced to

$$
\mathrm{q}=\mathrm{f}\left(1, \quad \mathrm{p}_{\mathrm{f}}^{*}\right) \text {. }
$$

Note that the basis for the reduction deserves thought. If the reduction correctly describes the economy, then it is valid. However, if the reduction is for simplicity or by necessity (due to data unavailability, perhaps), then it could result in a specification error: the omission of prices which affect demand biases estimates of the effects of non-omitted variables. In the latter case, application of the homogeneity condition is invalid and it could further compound the specification error. It is important to note, however, that the central issue is not, as Timmer suggests [12, pp. 202-3, 221], the validity of the homogeneity condition-it is always valid if all prices are specified-but the relevance of omitted prices: if omitted prices are relevant, then these must be incorporated in the demand function in order to avoid specification error.

The static, linear estimation form for the reduced demand function is

$$
\mathrm{q}=\mathrm{a}+\mathrm{b}_{1}\left(\mathrm{p}_{\mathrm{f}}^{*}\right)+\mathrm{u}
$$

The logarithmic form

$$
\ln (q)=b_{0}+b_{1} \ln \left(p^{*}\right)+u
$$

is generally used, however, as the demand elasticity is constant and, simply, the relative price coefficient, $b_{1}$. In time series estimation, demand is likely to exhibit a trend over time which can be removed with the inclusion of a trend variable, $T$, in the demand function:

$$
\ln (q)=b_{0}+b_{1} \ln \left(p_{f}^{*}\right)+b_{2} T+u
$$

If trend is predominant, it is more appropriately removed by means of first differences. This involves the estimation of the function after subtraction of one-period, lagged function from the original. This yields the estimation form:

$$
\ln \left(\mathrm{q}_{\mathrm{t}} / \mathrm{q}_{\mathrm{t}-1}\right)=\mathrm{b}_{1} \ln \left(\mathrm{p}_{\mathrm{f}}^{*} / \mathrm{p}_{\mathrm{f}-1}^{*}\right)+\mathrm{b}_{2}+\left(\mathrm{u}_{\mathrm{t}}-\mathrm{u}_{\mathrm{t}-1}\right)
$$

Note that in the first difference form, the trend coefficient, $b_{2}$, is the intercept and, given the logarithmic specification, the relative price coefficient remains the demand elasticity. 
A dynamic estimation form is frequently used. It derives from the twoequation Nerlovian adjustment model [12]:

$$
\begin{array}{ll}
\ln (Q)= & b_{0}+b_{1} \ln \left(p_{i}^{*}\right)+u \\
\ln \left(q_{t} / q_{t_{-1}}\right) & =c_{0} \ln \left(Q^{\prime} / q_{t_{-1}}\right)
\end{array}
$$

where $Q$ is desıred, long-run equilibrium, fertilizer demand and $c_{o}$ is an adjustment coefficient of demand to its desired level. Elimination of $Q$ through substitution yields the estimation form

$$
\ln \left(\mathrm{q}_{\mathrm{t}}\right)=\mathrm{b}_{\mathrm{o}}+\mathrm{b}_{1} \ln \left(\mathrm{p}_{\mathrm{f}}^{*}\right)+\mathrm{b}_{2} \ln \left(\mathrm{q}_{\mathrm{t}-1}\right)+\mathrm{u}
$$

In this dynamic form, the short-run demand elasticity is $b_{1}$, while the long-run equilibrium elasticity is $b_{1} /\left(1-b_{2}\right)$; the adjustment coefficient is $1-b_{2}$. The principal drawback in the use of this form is that ordinary least-squares regression yields biased coefficient estimates when lagged dependent variables are considered independent [5].

For any of the above forms, there is controversy on the need to include additional variables-such as income, acreage, and irrigation-in the demand function. Although theory does not specify an income variable in input demand functions [4], lagged income is frequently included to allow for the effects of a capital constraint. However, even in this instance the need is not well substantiated as Timmer [12, p. 208] shows that, for the simple one-outputone-input model, a capital constraint does not influence the demand elasticity. Acreage and irrigation measures are frequently included, presumably because these are proxies for their respective relative prices and because these are important complements to fertilizer consumption. For micro data, the use of such proxies could yield meaningful results; but for aggregate time series data, in which the collinearity between such proxies and a time trend or lagged fertilizer consumption is high, their inclusion yields results difficult to interpret and therefore of little policy relevance. If the intention in the use of acreage and irrigation measures is to capture growth effects, then the preferred specification is to define demand as per acre or per irrigated acre. However, this specification yields an elasticity of the intensity of fertilizer use and it is not clear that this narrowly defined elasticity is the relevant elasticity for policy analysis as acreage and irrigated acreage are largely endogenous variables.

The final two methodological points are cautionary and concern the proper identification of the demand function from time series data. First, shifts in supply accompanied by shifts in demand, induced by the Green Revolution, for instance, do not permit identification of the true demand reiationship. Second, when supply shortages and a fertilizer black market exist, identification of the true demand relationship requires that prices be observed not at their known, regulated levels but at their unknown, black market levels. The occurrence of both demand shifts and black market prices in the late Sixties prevents proper identification of the demand function for this period. Consequently, estimations of it must be viewed with caution.

\section{REVIEW OF PAST RESEARCH}

There have been four studies published in this Review. The first, by Leonard [7], appeared in 1969; the second, by Ayub [2], appeared in 1975; the third, by Chaudhry and Javed [3], appeared in 1976; and the fourth, by Salam 
[11], appeared in 1977. All the four studies estimate similar demand functions for aggregate time series data of about the same time period. Their results are presented in Table 1. We review each study in its chronological order.

\section{Leonard, 1969}

Although the first and written as a Note, this study is the most thorough of the studies under review. It is the only study to estimate all four of the standard functional forms - linear, log, first difference, and adjustment. These are estimated for 16 years' (1952-1968) aggregate national (West Pakistan) data. Regrettably, the data are not discussed. Though all fertilizer demand is analyzed, it is measured in ammonium sulphate equivalent and so, essentially, the analysis is relevant for nitrogenous fertilizer.

Demand is expressed as a function of a price variable and, for the linear and $\log$ forms, a time trend. The price variable is defined as the ratio of nominal price to a nominal index of agricultural income. The difficulty with this definition is that agricultural income is the product of output price and quantity and so the price variable is a proxy for relative prices only when output quantity is constant. As output has increased over time, the price variable will exhibit a biased downward trend. ${ }^{3}$ Consequently, if prices have fallen (risen) over time, then the price elasticity-ignoring the negative sign-will be underestimated (overestimated).4

${ }^{3}$ Since the specification is incorrect, we ignore the added difficulty of the fact that output is an endogenous variable.

"Proof: For simplicity, replace the index of agricultural income by the simple product of quantity and price of an arbitrary output. Let $q=$ quantity of fertilizer, $0=$ quantity, of output, $p=$ price of fertilizer relative to the price of output, $n=$ relative price elasticity, $n^{\star}=$
Leonard's estimated $n$, and $t=$ time. Also, let prime superscripts denote all time derivatives. Since all variables are a function of time, by definition,

$$
\mathrm{q}^{\prime}=\frac{\mathrm{dq}}{\mathrm{dp}} \mathrm{p}^{\prime}=\frac{\mathrm{dq}}{\mathrm{d}(\mathrm{p} / \mathrm{o})}(\mathrm{p} / \mathrm{o})^{\prime}
$$

or, rearranging,

$$
\frac{d q}{d p}=\frac{d q}{d(p / o)} \frac{(p / o)^{\prime}}{p^{\prime}}
$$

Furthermore,

$$
\frac{d q}{d p} \frac{p}{q}=\frac{d q}{d(p / o)} \frac{(p / o)^{\prime}}{p^{\prime}} \frac{p}{q} \frac{o}{o}
$$

or, simply,

$$
\begin{aligned}
& \mathrm{n}=\mathrm{n}^{*} \quad \mathrm{o} \frac{(\mathrm{p} / \mathrm{o})^{\prime}}{\mathrm{p}^{\prime}}=\mathrm{n}^{*} \frac{\mathrm{o}}{\mathrm{p}^{\prime}} \frac{o \mathrm{p}^{\prime} \longrightarrow \mathrm{po}^{\prime}}{\infty \mathrm{o}} \\
& =\mathrm{n}^{*}\left(1-\frac{\mathrm{po}^{\prime}}{\mathrm{op}^{\prime}}\right)
\end{aligned}
$$

Now, since $o^{\prime}$ is positive, if $p^{\prime}$ is negative (positive), then $n^{*}$ is less (greater) than $\mathbf{n}$ in absolute value. If $\mathrm{p}^{\prime}$, is positive, then $\mathrm{n}^{*}$ could be positive even though $\mathrm{n}$ is negative as when po'/op' exceeds unity. 
Table 1

Results of Past Research

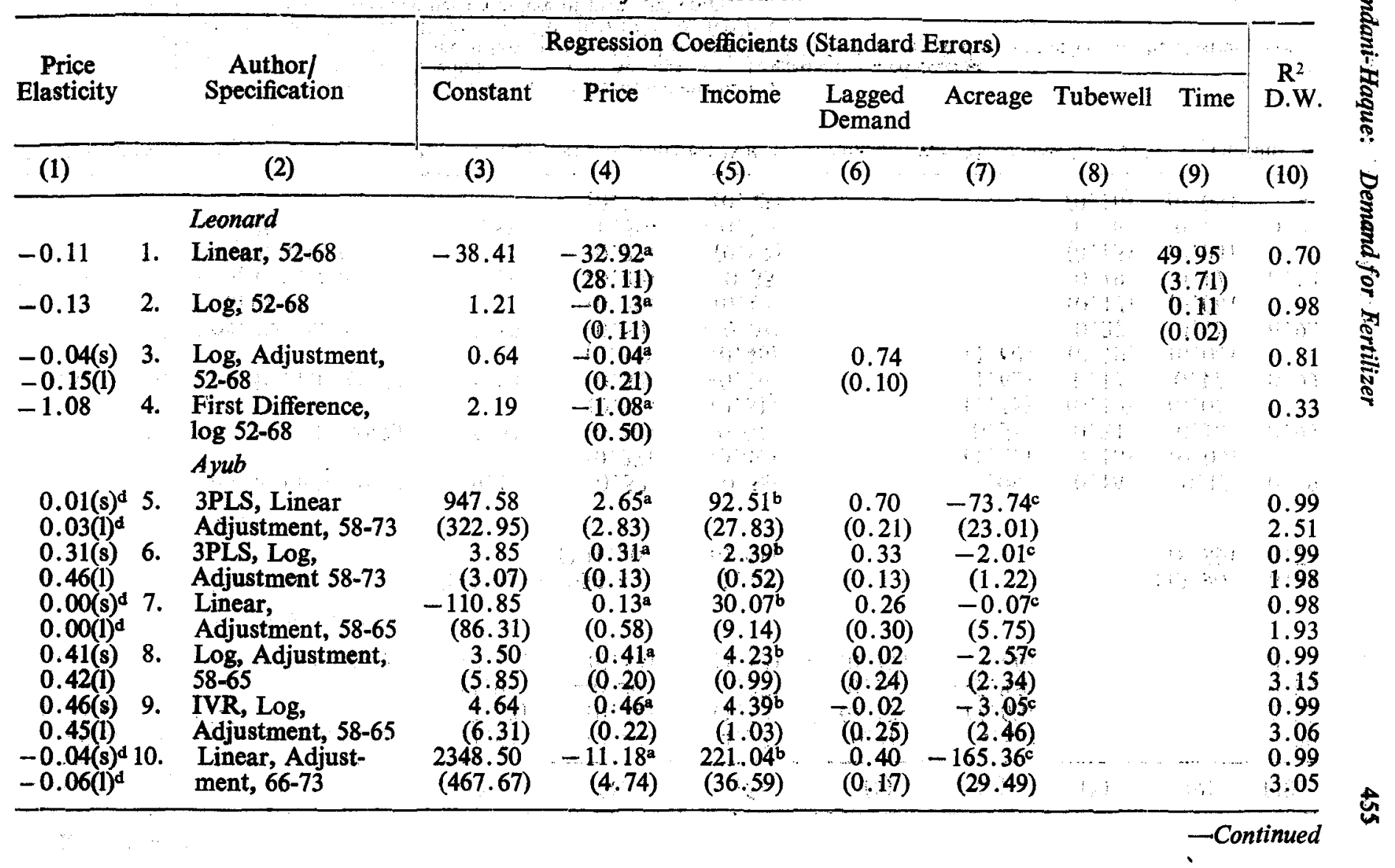


Table 1-Contd.

\begin{tabular}{|c|c|c|c|c|c|c|c|c|c|c|}
\hline (1) & & $(2)$ & (3) & (4) & (5) & (6) & (7) & (8) & (9) & (10) \\
\hline $\begin{array}{l}-0.49(\mathrm{~s}) \\
-0.58(1) \\
-0.49(\mathrm{~s}) \\
-0.58(1)\end{array}$ & $\begin{array}{l}11 . \\
12 .\end{array}$ & $\begin{array}{l}\text { Log, Adjustment, } \\
\text { 66-73 } \\
\text { IVR, Log, } \\
\text { Adjustment, 66-73 }\end{array}$ & $\begin{array}{l}11.91 \\
(7.17) \\
11.93 \\
(7.17)\end{array}$ & $\begin{array}{r}-0.49 \mathrm{a} \\
(0.54) \\
-0.49 \mathrm{a} \\
(0.54)\end{array}$ & $\begin{array}{c}4.37 \mathrm{~b} \\
(1.53) \\
4.37 \mathrm{~b} \\
(1.53)\end{array}$ & $\begin{array}{l}0.16 \\
(0.17) \\
0.16 \\
(0.17)\end{array}$ & $\begin{array}{r}-4.84^{\mathrm{c}} \\
(2.60) \\
-5.85 \mathrm{c} \\
(2.60)\end{array}$ & & & $\begin{array}{l}0.99 \\
2.82 \\
0.99 \\
2.82\end{array}$ \\
\hline$\because$ & & Chaudhry-Javed & & & & & & & & \\
\hline \multirow[t]{2}{*}{-1.21} & 13. & Linear, $66-74$ & 242.00 & $\begin{array}{r}-1059.80^{\circ} \\
(191.30)\end{array}$ & $\begin{array}{r}1.40^{f} \\
(0.51)\end{array}$ & & & & $\begin{array}{r}113.90 \\
(8.89)\end{array}$ & $\begin{array}{l}0.99 \\
2.76\end{array}$ \\
\hline & & Salam & & & & & & & & \\
\hline-0.52 & 14. & Log, Punjab, 60-73 & -9.18 & $\begin{array}{c}-0.528 \\
(0.27)\end{array}$ & $\begin{array}{c}-0.58^{\mathrm{h}} \\
(0.49)\end{array}$ & & $\begin{array}{r}2.08^{\mathrm{i}} \\
(1.27)\end{array}$ & $\begin{array}{c}0.16 \\
(0.16)\end{array}$ & $\begin{array}{c}0.15 \\
(0.04)\end{array}$ & 0.99 \\
\hline-0.44 & 15. & Log, Punjab, 60-73 & 5.03 & $\begin{array}{r}-0.44 k \\
(0.31)\end{array}$ & $\begin{array}{r}-0.07^{\mathrm{h}} \\
(0.51)\end{array}$ & & $\begin{array}{r}0.55 \mathrm{j} \\
(1.55)\end{array}$ & $\begin{array}{c}0.24 \\
(0.19)\end{array}$ & $\begin{array}{c}0.16 \\
(0.06)\end{array}$ & 0.99 \\
\hline-0.52 & 16. & Log, Punjab, 60-73 & -5.04 & $\begin{array}{r}-0.528 \\
(0.31)\end{array}$ & $\begin{array}{r}-0.26^{\mathrm{h}} \\
(0.46)\end{array}$ & & $\begin{array}{l}1.62^{k} \\
(1.60)\end{array}$ & $\begin{array}{c}0.12 \\
(0.19)\end{array}$ & $\begin{array}{l}0.17 \\
(0.04)\end{array}$ & 0.99 \\
\hline-0.50 & & $\begin{array}{l}\text { Log, Per Acre, } \\
\text { Punjab, 60-73 }\end{array}$ & 1.35 & $\begin{array}{r}-0.50 \mathrm{~g} \\
(0.30)\end{array}$ & $\begin{array}{c}-0.01^{\mathrm{h}} \\
(0.44)\end{array}$ & & & $\begin{array}{c}0.27 \\
(0.17)\end{array}$ & $\begin{array}{c}0.15 \\
(0.04)\end{array}$ & 0.98 \\
\hline-0.49 & & $\begin{array}{l}\text { Log, Per Acre, } \\
\text { Punjab, } 60-73\end{array}$ & 3.59 & $\begin{array}{r}-0.498 \\
(0.27)\end{array}$ & $\begin{array}{c}-0.35^{h} \\
(0.97)\end{array}$ & & & $\begin{array}{c}0.19 \\
(0.15)\end{array}$ & $\begin{array}{c}0.17 \\
(0.04)\end{array}$ & 0.98 \\
\hline-0.50 & & $\begin{array}{l}\text { Log, Per Acre, } \\
\text { Punjab, 60-73 }\end{array}$ & 2.55 & $\begin{array}{r}-0.508 \\
(0.28)\end{array}$ & $\begin{array}{r}-0.21^{\mathrm{h}} \\
(0.42)\end{array}$ & & & $\begin{array}{c}0.16 \\
(0.16)\end{array}$ & $\begin{array}{c}0.17 \\
(0.04)\end{array}$ & 0.98 \\
\hline
\end{tabular}

Notation: $\mathrm{s}=$ short-run; $1=$ long-run; $3 \mathrm{PLS}=$ three-pass least squares; IVR $=$ instrumental variables regression; D.W. $=$ DurbinWatson statistic.

Note: a. Price $=$ Price of fertilizer relative to agricultural income index.

b. Income $\rightleftharpoons$ Agricultural income index. c. Acreage $=$ Lagged cultivated acreage.

d. The elasticity is measured at the mean level reported by Leonard for 1952-1968 as Ayub does not calculate the elasticity nor provide the mean level. e. Price Nominal price of fertilizer.

f. Income $=$ Nominal revenue per crop-acre of principal crops.

g. Price $\Longrightarrow$ Price of fertilizer relative to weighted price index of major crops.

h. Income $=$ Lagged weighted price index of major crops. i. Acreage $=$ Acreage of major crops.

$j$. Acreage $=$ Acreage of total crops. $k$. Irrigated esceage. 
With the exception of the first difference form, all forms yield insignificant coefficients for the price variable. Due to the likelihood of negative correlation between the price variable and the time trend, an insignificant price coefficient is not unexpected. This remark also applies to the adjustment form as fertilizer demand has increased rapidly over time and so its lagged transform is correlated with the trend variable and would, therefore, have an analogous effect. In addition to the multicollinearity problem, as the relative price of fertilizer fell generally during the period $1952-1968$, the price coefficient would be expected to be small in view of the bias noted above. Hence Leonard's conclusion that the price elasticity is small and insignificant is unwarranted.

The first difference estimation is of interest. Given the predominance of trend in the data, first differences do, as expected, surmount the multicollinearity problem. The price coefficient is significant at the 95 percent probability level. Somewhat surprisingly, although the coefficient is known to underestimate the price elasticity, it is (in absolute value) slightly above unity. Note that, as mentioned in the methodology part of this section, the price elasticity is not short-run, as Leonard states, but the usual elasticity implied by the log form.

Our review suggests revision of Leonard's conclusions, in particular, the conclusion that the price elasticity of fertilizer demand, while significant in the short-run, is insignificant in the long-run and so reduction of the price subsidy is desirable. Since the first difference elasticity is not short-run, the distinction between short-run and long-run is inapplicable; and since the insignificant estimations have both bias and multicollinearity problems, these are unreliable. The only reliable result is the significant, unit elasticity estimate of the first difference form. There is, therefore, some evidence that the price elasticity of fertilizer demand is significant at unity, and no reliable evidence that it is insignificant or that removal of the price subsidy is desirable.

\section{Ayub, 1975}

The second study, also a Note, is largely a comment on the first. Its principal concern is the re-estimation of the adjustment model with explicit allowance for simultaneity. Regrettably, the data are also not discussed. It is unclear but presumably the data are the same as Leonard's data; the re-estimation, however, is for a more recent time period, 1958-1973, also 16 years. Estimations are further made for the subperiods 1958-1965 and 1966-1973.

Ayub begins with two incorrect objections to Leonard's significant, unit elasticity, first difference form estimate. First, he maintains that Leonard's specification of the first difference form, which includes an intercept, is erroneous. Second, he maintains that the coefficient of the price variable in the first difference form of the log model is not an elasticity estimate. These objections are not valid, however, as shown in the methodology part of this section. Unfortunately, Ayub does not further investigate the first difference form or the reasons for Leonard's significant estimate.

Instead, Ayub investigates the insignificance of the adjustment form estimation. On the speculation that the insignificance is attributable to simultaneity and autocorrelation, the ajdustment form is re-estimated with three- 
pass least squares. ${ }^{5}$ However, two variables additional to the downward biased price variable and the lagged endogenous variable are included in the estimation: lagged cultivated acreage and the nominal index of agricultural income, the denominator of the price variable. As asserted in the methodology part of the section, inclusion of such additional variables is not desirable. Moreover, the specification of demand as a function of lagged acreage and current nominal income rather than current acreage and lagged real income is incorrect. Consequently, assessment of the results is difficult.

The results are unexpected: the elasticity estimates are positive and, in the log version of the adjustment model, significant at the 95 percent probability level. Without interpretation, Ayub rejects these as unsatisfactory and, in the process, also dismisses the usefulness of three-pass least squares. This is unfortunate. We think the unexpected results are attributable to specification error rather than to the use of three-pass least squares. Specifically, had Ayub re-estimated Leonard's adjustment form without additional variables, we conjecture that the results would have been similar to Leonard's results.

The direction of the specification error can only be guessed. Since the income variable is significant in the log adjustment form, consider, for simplicity, the specification error of including it in the regression of demand on the price variable. As the income variable is the denominator of the price variable, the two are likely to be strongly and negatively correlated. If the product of the latter correlation with the strong positive correlation between demand and income exceeds, in absolute value, the correlation between demand and the price variable, then the estimated price elasticity will be positive even though the true elasticity is negative [5]. Whether this is the explanation for the unexpected positive elasticity is not determinable without access to the original data correlation matrix; however, it is a possible explanation.

Ayub next estimates the above model for the subperiods 1958-1965 and 1966-1973 on the presumption that the price elasticity is not constant but increasing over time due to changing demand conditions. The results, however, are unimpressive: five out of six elasticity estimates are insignificant and the sixth, a linear adjustment form estimate for the latter subperiod, yields a low elasticity of -0.04 . We conjecture that the unimpressive results are due to the above specification error and, as mentioned in the methodology part of this section, the fact that identification of the true demand function for the latter subperiod is difficult due to the existence of supply shortages and a fertilizer black market. Surprisingly, Ayub ignores the significant elasticity estimate and prefers, without any stated reason, the insignificant, log adjustment form estimates for the latter subperiod of -0.49 ; also surprisingly, Ayub compares these insignificant elasticity estimates with Leonar'ds insignificant simple log elasticity estimate of -0.13 and concludes from the comparison that the elasticity has risen over time and so reduction of the fertilizer price subsidy is undesirable. Such analysis is unwarranted and should be discounted.

Our review finds little merit in Ayub's analysis. Leonard's only interesting result-the first difference estimation-is incorrectly dismissed. The re-

${ }^{5}$ Note, though, that the use of three-pass least squares removes the simultaneity between demand and lagged demand, and not that between demand and output, the divisor in the incorrectly specified price variable. 
estimation of Leonard's adjustment form is incorrectly specified and so it is unable to show the extent of simultaneity or autocorrelation difficulty in Leonard's estimation which is the stated intent of the re-estimation. The subperiod analysis is innovative but inconclusive and does not suggest that the price elasticity of fertilizer demand is increasing over time or that removal of the price subsidy is undesirable. Furthermore, the analysis is particularly weak as it ignores the identification problem inherent in the estimation of a demand function for the late Sixties.

\section{Chaudhry and Javed, 1976}

Unlike the preceding two studies, the third study is not a Note but an article; in fact, it is the lead article of the Review issue in which it appeared. However, it is a simple effort. It presents a single, linear demand estimation and a single, straightforward but strongly stated policy conclusion. The estimation pertains to nitrogenous fertilizer in nutrient equivalent and is for nine years, 1965-1966 to 1973-1974, a period almost identical to Ayub's second subperiod, 1966-1973. Incidentally, the policy conclusion is controversial and has provoked a comment by Afzal [1]; we mention but do not review the comment as it provides some qualifications but no alternative estimation or suggestions for estimation.

Chaudhry and Javed differentiate their estimation from those of Leonard and Ayub in three respects. First, they specify the demand function in nominal terms. Although a nominal demand function is sometimes useful for price projections, it is an incorrect specification for the estimation of a price elasticity. It is incorrect because it allows a simple change in the unit of price measurement to affect demand. As there is no unique relation between percentage changes in real and nominal prices, the direction of bias of the specification error cannot be determined.

Second, the authors define the output price variable as revenue per cropped acre. They do so to allow for changes in output price and yield per acre. This specification is incorrect, however, as, as shown in the methodology part of this section, fertilizer demand is not a function of yield. 6 The consequent specification error is of the same type as that committed by Leonard and Ayub: since yield has increased over time, the nominal output price variable will exhibit a biased upward trend and so, if output prices have risen (fallen) over time, then the nominal output price elasticity will be underestimated (overestimated). Note, though, that while the earlier authors misspecify a relative price variable, Chaudhry and Javed misspecify the output price variable and not the fertilizer price variable.

Third, the authors utilize annual demand and fertilizer price data defined for the agricultural year (March to February) instead of the usual fiscal year (July to June). They do so in the belief that the redefinition better approximates the time cycle of fertilizer use. It is unclear how the data are converted to the agricultural year. In any case, the redefinition is trivial: correlation is sought between variables in the same time period; whether the period

\footnotetext{
'Incidentally, even if demand is a function of yield, the specification still is incorrect as the simultaneity between yield and demand is not factored out of the demand function prior to
estimation.
} 
is the calendar year, fiscal year, or agricultural year is irrelevant. Surprisingly, the output price variable is not redefined; strict interpretation of the variable is nonsensical, therefore.

For the above specification, the authors report only one estimation. They estimate demand as a linear function of nominal fertilizer price, nominal revenue per crop-acre, and a time trend. Their choice of the linear form is based on an erroneous impression that Ayub had experimented with different types and had recommended the linear form. This is incorrect: Ayub only estimated the adjustment form. Clearly, it is desirable that forms other than the simple linear form are estimated. In any case, their linear estimation is significant and it yields nominal elasticities for fertilizer price and revenue per cropacre of -1.21 and 0.74 , respectively, measured at the mean level.

The authors are confused on the policy implications of their estimation. They conclude that demand is price-responsive. Yet, they recommend the removal of the fertilizer price subsidy. Clearly, the opposite recommendation is necessary. This point is the essence of the comment by Afzal [1].

Although significant, we consider the estimation too problematic to warrant a policy discussion; instead, we suggest its implications for further estimation. To begin with, the revenue per crop-acre variable should be regarded simply as output price variable; as such, the variable is biased upward and so its elasticity must be regarded as underestimated. A cautious view would regard the nominal input and output price elasticities to be roughly equal at about unity (but opposite in sign). The rough equivalence could then imply that the nominal specification is perhaps acceptable (as inflationary price changes cancel), and, for that matter, the relative price specification is perhaps also acceptable. The estimation suggests, therefore, that traditional demand specifications could yield similar price elasticities of unity; we emphasize, though, that this is only incidental conjecture.

Our review finds little merit in the analysis of Chaudhry and Javed. The demand specification is erroneous; the single estimation is insufficient; and the policy discussion is misleading. Like Ayub, the authors ignore the fundamental identification problem inherent in the estimation of a demand function for the late Sixties. Given the deficiencies, though, there is incidental evidence of a unit fertilizer price elasticity and this does compare, coincidentally, with Leonard's only sigificant estimate. Finally, the linear estimation form appears to provide a good fit to the data and this could explain the difference in significance between the results of Ayub and those of Chaudhry and Javed.

\section{Salam, 1977}

The fourth and most recent study, also an article, is, in fact. in coverage less recent than the third and not more recent than the second. The period of analysis is 14 years, $1959-1960$ to $1972-1973$. However, the analysis is effective for 11 years, $1962-1963$ to $1972-1973$, as demand and price data for the three years, 1959-1960 to 1961-1962, are backward trend projections. This effective period of analysis is a subset of the periods analyzed by Ayub and by Chaudhry and Javed (although the latter only report results for later years). Unlike these authors, though, Salam does not consider subperiod analysis and his interest is 
confined to the demand for nitrogenous fertilizer (in nutrient equivalent) in the Punjab.

Salam confines the analysis to the Punjab in the expectation that demand analysis for a homogeneous region is likely to yield better results than national analysis. Two remarks are in order. First, although better results are possible, these should not be very different as the Punjab accounts for 70 percent of national demand. In fact, as the Punjab's share of national demand has been stable over time and as price is uniform nationally, the price elasticity for the Punjab should equal that for the nation. Incidentally, this hypothesis is easily testable with Salam's data but he does not attempt the test, however.

Second, the possibility of better results must be considered together with the possibility of worse results due to scant disaggregated data for the Punjab. In this regard, the usefulness of Salam's backward data projection in order to ensure minimal estimation degrees of freedom is questionable. Regional analysis, therefore, is not necessarily superior to national analysis. We think the focus of regional analysis should be to corroborate the results of national analysis. Regrettably, this is not the focus of the study: Salam presents elasticity estimates for the Punjab without any attempt to reconcile these with national estimates, either earlier estimates or his own; in fact, Salam does not even attempt a simple comparison of his estimates with earlier estimates.

Salam specifies demand as a function of relative price, lagged nominal output price, number of tubewells, acreage, and a time trend. In addition, the specification is varied in two ways to determine its sensitivity to alternative definitions of acreage. First, three acreage variables-major crop, total crop, and irrigated acreage-are successively introduced as independent variables in the demand function. Second, the same variables are successively re-introduced but as demand deflators. This procedure defines demand per acre and yields as price elasticity of the intensity of fertilizer use.

In the calculation of relative price and lagged nominal output price, Salam computes output price as a weighted price index of six crops with crop production values for each year as variable weights. The advantage of a weighted average over a simple average is unclear; in any case, the use of variable weights instead of constant weights is problematic. To the extent that there is an output price effect, the use of variable weights tends to exogenize this endogenous effect and so underestimate it. Specifically, when prices that increase relatively more rapidly receive relatively gteater weight in the price index over time, there is an upward bias in the measurement of output price and an underestimation of the output price elasticity. Note, however, that there is the added complication of simultaneity between the production weights and demand. Hence, the overall effect of the misspecification on the estimation of the relative price elasticity is unclear.

Inclusion of lagged nominal output price in the demand specification is erroneous. Salam reasons that lagged output price is a proxy for current output price which, in turn, is a proxy for current income. Although lagged output price is a reasonable proxy for current output price, current output price is a poor proxy for current income. In any case, both proxies are unnecessary: in a relative price specification, current output price is already known (as it is the 
relative price denominator), while current income need not be known as it should not be included in an input demand function. ${ }^{7}$ As stated in the methodology part of this section, an income variable should not be specified in a fertilizer demand function; if it is, it is specified as lagged income which is known. and need not be proxied. Since lagged nominal output price is a poor proxy for lagged real income and since lagged output price is correlated with current. output price, the specification error will affect the elasticity estimate.

The inclusion of the acreage and tubewell variables in a demand function is of dubious value. As indicated in the methodology part of this section, these variables should not be specified in a demand function. Typically, these are highly correlated with the time trend; hence their separate effects are not easily differentiable and, thus, their inclusion contributes very little to policy analysis. Furthermore, the successive inclusion of different acreage definitions is also of dubious value as some may prove to be significant for the given data set simply because enough have been tried. Finally, although the demand per acre specification yields an elasticity of the intensity of fertilizer use, it is not clear that this narrowly defined elasticity is the relevant elasticity for policy analysis. We think the relevant elasticity should be broadly defined to include extensive as well as intensive demand responses to price as acreage is realistically an endogenous variable.

Salam estimates only one functional form: the log form. This is unfortunate for two reasons. First, earlier analyses suggest that demand estimations are sensitive to functional form: Leonard was successful with the first difference form, Ayub with the linear adjustment form, and Chaudhry and Javed with the linear form; all report different results. Since Salam does not estimate alternative functional forms it is unknown whether further differences in results are attributable to form. Second, the choice of the log form implies that the price elasticity is constant for the entire estimation period, an assumption not accepted by Ayub or by Chaudhry and Javed. Since Salam does not undertake subperiod analysis, the assumption is particularly restrictive.

Salam presents six estimations. As indicated, all are for the $\log$ form, and all differ in just one variable: acreage. As would be expected, therefore, the estimations are not very different. In every estimation, the time trend dominates and is significant while all other variables-price, income, tubewell, and acreage-with one exception, are insignificant. The significance criterion is the standard two-tail t-test at the 90 percent probability level.

The single exception is an elasticity estimate of -0.52 . It is difficult to accept this estimate. The significance appears to be a spurious consequence of the inclusion of an irrelevant variable-acreage of major crops-in the demand function as it disappears when the variable is deleted. In any case, the insignificance of all other (nontrend) estimates is attributable to the severe multicollinearity, evident in all estimations and so, given multicollinearity, the reliability of all estimates is doubtful. It is regrettable that Salam does not try to improve the results.

Surprisingly, Salam's conclusion is that relative price is an important determinant of demand. Furthermore, the policy conclusion is that relative

'If current income is specified in the demand function a simultaneity problem exists between demand and income which must be removed prior to estimation. 
price should not rise if demand is not to decline. Presumably, the implication of this is that Salam is opposed to the removal of the relative price subsidy. However, Salam does not discuss the price subsidization issue. In any case, we think the results are inconclusive and do not warrant a policy discussion.

Our review finds little merit in Salam's analysis. The specification is erroneous; the single estimation form is insufficient; subperiod analysis is ignored; and the estimations are insignificant. Salam's two innovations-analysis for the Punjab and of demand per acre-are inconsequential. The only significant estimate of a price elasticity of one-half does not compare with earlier estimates but, coincidentally, the insignificant elasticity estimates do compare with Ayub's insignificant estimates. Bear in mind, though, that Salam's estimates pertain to the Punjab. Finally, like all earlier authors, Salam ignores the fundamental identification problem inherent in the estimation of a demand function for the late Sixties.

\section{CONCLUSIONS}

Our review of past research finds no reliable estimate of the price elasticity of fertilizer demand. Among 28 estimates by four separate studies of aggregate annual data for roughly the same time period, only seven are significant. However, even these seven are unsatisfactory because of such limitations as incorrect specification and the like. Moreover, these range widely from -1.21 to +0.46 and are largely noncomparable due to differences in definition, functional form, and the inclusion of different, extraneous variables in the demand function. To the limited extent that comparison is possible, these elasticities appear to reconcile to about unity but this is a bold assertion.

The poor results are partly attributable to the inadequacy of past research. Our review indicates serious mistakes in past reasearch; regrettably, many of these are common to more than one study and so should have been avoided by later researchers had they reviewed the efforts of earlier researchers. Such mistakes include the persistent misspecification of key variables, analysis of irrelevant variables, emphasis on a single estimation form, and disregard of the prevalence of multicollinearity in the data. All studies ignore the fundamental identification problem inherent in the estimation of a demand function for the late Sixties. It is possible, therefore, that a rigorous analysis could yield better results.

The poor results are also partly attributable to the inadequacy of aggregate data. The data suffer from insufficient degrees of freedom and are for a time period in which frequent demand shifts and supply shortages are known to have occurred. Estimation of a demand function with such data may not be possible. Clearly, therefore, the better results of rigorous analysis need not be good results. We think the inadequacy of aggregate data is the binding constraint to the attainment of good results.

To show their inadequacy, we plot the data. Figure 1 is a plot of national fertilizer consumption, $q$, and the relative price of fertilizer, $p^{*}$, for 16 years, 1961-1962 to 1976-77. We are unable to obtain price data for earlier years and so are not able to analyze the period 1952 to $1960-1961 .^{8}$ Consumption, $q$,

${ }^{8}$ Although both Leonard and Ayub analyze earlier data, they do not report either the data or their source; so we are unable to obtain the data. 


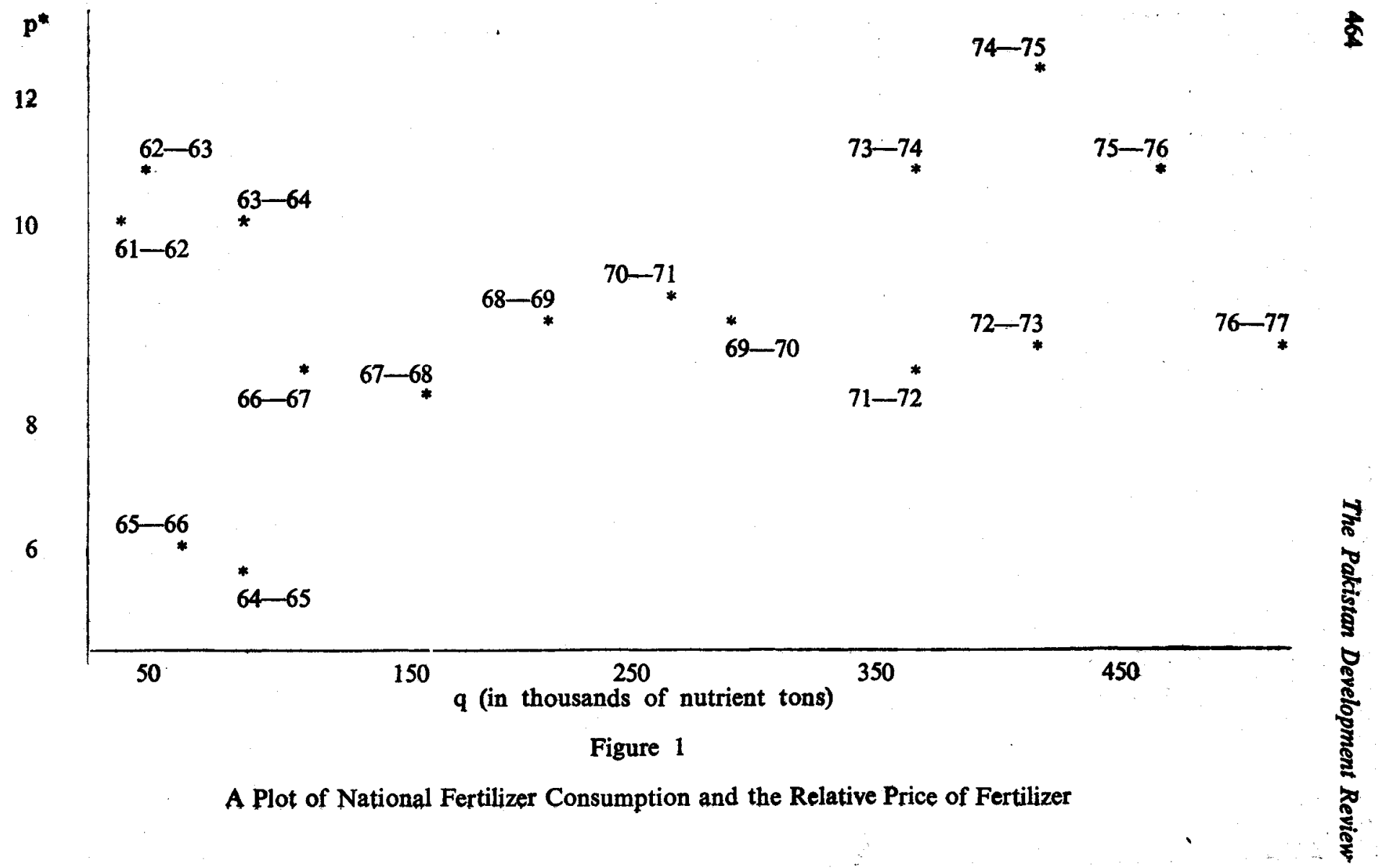


pertains to nitrogenous fertilizer in nutrient tons, while relative price, $p^{*}$, is the ratio of the nominal sale price of Urea fertilizer (in Rupees per nutrient ton) to a simple average of the nominal price indices of cotton, rice, and wheat." Although similar data are available at the regional level for each province for the years 1965-1966 to 1976-1977, we do not present their plots as these are almost identical (except in scale) to that for the national data.

The plot of the data shows their inadequacy. The plot is scattered and, certainly, it is not downward sloping. Generally, demand (with three exceptions) and price (with five exceptions) have increased over time. Although the exceptions are mutually exclusive and so half the data (for eight years) conform with a demand pattern, these are not contiguous but scattered at the two end-points of the time period. Overall, no clear relationship between demand and price is apparent.

Although the plot for 1961-1962 to 1965-1966 displays a demand pattern, it is misleading. In 1964-1965, we observe an inelastic demand response (of 25 percent) to a price decline (of 47 percent), while in 1965-1966, we observe an elastic demand response (of -23 percent) to a price rise (of 12 percent). Are these true demand responses? We think not: in 1964-1965, known supply shortages probably constrained the growth in demand, while in 1965-1966, a drought, the war with India, and the subsequent cut-off of American commodity aid necessitated a reduction in demand $[6, \mathrm{p} .118]$. Since exogenous factors explain seemingly price-motivated movements in demand, the data are not useful for demand analysis.

Although the plot for 1965-1966 to 1969-1970 does not display a demand pattern, it is not unexpected. In this period, demand increases are disproportionate and in some cases considerable while price movements are not equally erratic. The former pattern is expected given, the irregularities in supply which are known to have occurred as well as likely demand shifts induced by the Green Revolution [6, pp. 118-32]. The latte1 pattern is also expected as price movements are for observed, regulated prices and not for the true equilibrium, black market prices which are known to have prevailed during the period [6, p. 119]. Since simultaneous demand and supply shifts and the existence of black markets prevent the identification of a demand pattern, the data
are not useful for demand analysis.

Although the plot for 1969-1970 to 1971-1972 displays a demand pattern, it, too, is misleading. In both 1970-1971 and 1971-1972, we observe highly elastic demand responses to minor price changes. Again, these are not true demand responses. A severe drought and the events leading to the secession of East Pakistan explain the initial decline (in 1970-1971) and the later rapid rise (in 1971-1972) in fertilizer consumption [8,9j. Since these demand movements are explained by nonprice factors, the data are not useful for demand analysis.

'Since Urea is the predominant nitrogenous fertilizer consumed, the price of Urea is an acceptable measure of the price of nitrogenous fertilizer. Also, since cotion, rice and wheat are the principal output crops, a simple average of their prices is an acceptable measure of output price. Dala sources are [10, p. 186] for demand, [10, p. 194] for fertilizer price, and [10, Table $29(A)]$ for output prices. These sources are periodic publications; recent data are
from forthcoming editions of these publications. 
The plot for 1972-1973 to 1976-1977 suggests a demand pattern. Moderate price movements are evident for the period and, for a change, these are accompanied by apparently genuine demand responses. The price changes are attributable to a recently revised policy of gradual reduction of the fertilizer price subsidy. Note that implementation of the policy has been flexible and that the fertilizer price has been raised as well as lowered. The demand responses appear genuine: during this period, there were no observed supply shortages or black markets, and, furthermore, it is generally recognized that the initial impact of the Green Revolution had worked itself out prior to the start of this period. However, there were floods in August and September of 1973 and 1976, and a dry spell from April, 1974 to February, 1975, which could have had an effect on fertilizer consumption. Although these data are useful for demand analysis, unfortunately, these provide insufficient degrees of freedom for aggregate analysis.

Overall, the plot explains the poor results of past research. The lack of a clear relationship between demand and price explains the many insignificant estimations of past research. The strong trend in demand explains the consistent significance of the time trend in otherwise insignificant estimations, while a trend in price suggests the presence of multicollinearity, a problem ignored in past research. Finally, we speculate that isolated "cases" of both elastic and inelastic demand patterns in an otherwise trend-dominated scatter could be picked up in past estimations circumstantially (due to the arbitrary inclusion of extraneous trend-dominated variables, and the arbitrary use of particular estimation forms and particular time periods) and thus explain the occasional occurrence of a significant elasticity estimate. Salam's inelastic estimate could be due to the observation for 1965-1966, while the Chaudhry and Javed elastic estimate could be due to the observation for 1971-1972. It is important therefore, given such data, to ignore occasional results of this type.

The conclusion of this paper is straightforward. The review of past research is inconclusive as past research suffers from substantive theoretical and econometric difficulties, and severe data inadequacies. We do not recommend a correction and re-estimation of past reasearch as the inadequacy of aggregate data is the binding constraint to the attainment of meaningful results. We do think that the data for the early Seventies are adequate. A warning to future researchers, however: supply shortages did reappear in 1977-1978 and it is possible that current data may still be inadequate.

\section{REFERENCES}

1. Afzal, M. "Demand for Nitrogenous Fertilizers and Fertilizer Price Policy in Pakistan: A Comment." The Pakistan Development Review. Vol. XV, No. 3. Autumn 1976. pp. 330-333.

2. Ayub, Mahmood A. "An Econometric Study of the Demand for Fertilizers in Pakistan." The Pakistan Development Review. Vol. XIV, No. 1. Spring 1975 . pp. 135-141. 
3. Chaudhry, M. Ghaffar and M. Anwar Javed. "Demand for Nitrogenous Fertilizers and Fertilizer Price Policy in Pakistan." The Pakistan Development Review. Vol. XV, No. 1. Spring 1976. pp. 1-9.

4. Henderson, James M. and Richard E. Quandt. Microeconomic Theory. New York: McGraw-Hill. 1958.

5. Johnston, J. Econometric Methods. Second Edition. New York: McGraw-Hill. 1972.

6. Kahnert, F. R. Carmignani; H. Stier and P. Thomopoulos. Agriculture and Related Industries in Pakistan. Paris: Development Centre of the Organisation for Economic Cooperation and Development. 1970.

7. Leonard, P. L. "A Note on the Demand for Fertilizer in West Pakistan." The Pakistan Development Review. Vol. IX, No. 4. Winter 1969. pp. 419-425.

8. Pakistan. Finance Division. Economic Adviser's Wing. Pakistan Economic Survey 1970-1971. Islamabad. 1971.

9. 1974. Pakistan Economic Survey 1973-1974. Islamabad.

10. Ministry of Food, Agriculture, Co-operatives, Under Developed Areas and Land Reforms. Agricultural Statistics of Pakistan 1975. Vol. I and II. Islamabad. 1975.

11. Salam, Abdul. "Economic Analysis of Fertilizer Demand in the Punjab." The Pakistan Development Review. Vol. XVI, No. 2. Summer 1977. pp. 181-191.

12. Timmer, C. Peter. "The Demand for Fertilizer in Developing Countries." Food Research Institute Studies. Vol. XIII, No. 3. 1974. 